\title{
Spatial Distribution of Qualitative Characteristics and Production Factors of Kiwifruit at "Beira Litoral", Portugal
}

\author{
T. Panagopoulos and M.D.C. Antunes \\ University of Algarve \\ Centro de Investigação sobre Espaço e Organizações (CIEO) \\ IBB-Centro de Biotecnologia Vegetal \\ Campus Gambelas, 8005-139 Faro \\ Portugal
}

Keywords: kiwifruit, integrated management, geographic information system, geostatistics

\begin{abstract}
Objective of the present research was to generate information about the evolution of production factors and qualitative characteristics of 100 geo-referenced orchards of Beira Litoral-Portugal during three consecutive years. Graphical interpretation of quantitative and qualitative characteristics of kiwifruit production was done using GIS, geostatistics. Maps of biophysical characteristics of the region were then related to the areas of higher production and quality and it was studied their evolution over time. Those maps help to make decisions about harvesting time or localized correction of production factors and to choose the adequate location for vineyard installation in the region. Despite our enthusiasm for this technology, we are not proposing that it is a solution to all crop management problems or that it is appropriate for every operation. Meanwhile, we believe that the use of GIS and geostatistics provides a tool for sustainable production.
\end{abstract}

\section{INTRODUCTION}

The introduction of Actinidia deliciosa in Portugal represents a case of success in fruit production. Rapidly became one of the main crops in Northwest Portugal. Nowadays, there is a growing need for improved knowledge of product origin and its traceability through the supply chain. However, information on qualitative characteristics and production factors of this crop in this soil/climate zone is scarce (Panagopoulos et al., 2007).

Geographic information systems (GIS) and geostatistics are tools that are becoming progressively more suitable in fields of research like agriculture (Basso et al., 2001). Geostatistics are statistical methodologies that use spatial coordinates to help formulate models used in estimation and prediction. The major application of geostatistics in agriculture is in soil science to model and predict crop yield (Bresler, 1989). Localized problems in soil properties could be solved with simple, geographically restricted amendment treatments (Horney et al., 2005).

The combination of geostatistics and GIS has proved to be a solid base in the development of precision agriculture, which is based on the exact knowledge of actual soil conditions and yields (Yalouris et al., 1997; Kaffka et al., 2005). Traditional surveys of soil fertility, together with data from soil survey maps, can be used in combination with geostatistics by decision-makers to support management planning and to predict indicators related to land quality as a measure of sustainability (Diodato and Ceccarelli, 2005).

The objective of the present research was to generate information about the evolution of production factors and qualitative characteristics of 100 geo-referenced kiwifruit (Actinidia deliciosa 'Hayward') orchards of Beira Litoral-Portugal during three consecutive years. 


\section{MATERIAL AND METHODS}

The study area is located in Northwest Portugal (Beira litoral) with kiwi orchards laid out in a series of small blocks (0.5-1 ha). Kiwifruit vines were trained onto horizontal structure approximately $2 \mathrm{~m}$ above the ground, known as a pergola. A GIS and Global Positioning System (GPS) were used to develop digital maps of orchards. The ArcGIS 9.1 software was used to integrate maps as a series of data layers, aerial photographs and GPS coordinates. Edafoclimatic data of the region was acquired from digital environmental maps. It was collected data for kiwifruit for various qualitative characteristics such as ${ }^{\circ}$ Brix for four calibers (C1: 65-75 g; C2: 75-85 g; C3: 85-105 g; C4: >105 g).

Graphical interpretation of quantitative and qualitative characteristics of kiwifruit production was done using GIS and geostatistics as described from Panagopoulos et al. (2006) and maps of kiwi fruit production factors and fruit quality were produced. Maps of biophysical characteristics of the region were then related to the areas of higher production and quality and it was studied their evolution over time. Those maps could help to make decisions about harvesting time or localized correction of production factors and to choose the adequate location for vineyard installation in the region.

\section{RESULTS AND DISCUSSION}

The first step was to generate a map of location of the orchards in the study region in Northwest Portugal. Then it was used climatic and digital soil maps of the study region that was overlaid in ArcGIS to find the optimal areas for kiwi production according to Norton (1994). It was observed that good conditions for kiwi production were everywhere in the study area.

Figure 1 shows maps of spatial distribution and time evolution of the organic matter in the years 2002, 2003 and 2004. It was observed that the northern part of the study region has higher organic matter contend than the south and that also has a gradual decrease with time passing. Figure 2 shows the spatial distribution and time evolution of the $\mathrm{Ca} / \mathrm{Mg}$ in three consecutive years between 2002 and 2004 . The ratio $\mathrm{Ca} / \mathrm{Mg}$ was higher in the southern and western part of the study area, without any significant changes with time. Figure 3 shows the spatial distribution and time evolution of the electric conductivity in the years 2002 to 2004 . Electric conductivity was higher in the central part of the study region but generally was low in entire study region and without significant changes during the study time. Those maps of the main soil parameters should be taken into consideration to improve productivity and quality and site-specific soil amendments could save money and decrease environmental impact.

Figure 4 shows the spatial distribution and time evolution of the kiwifruit commercial size in the years 2002 to 2004 . Those maps show that production is higher in the north-western part of the region but there is high variability from year to year in various locations.

In Figure 5, it was also observed that the bigger calibres had higher ${ }^{\circ}$ Brix in the northeaster part of the study area. No changes where verified during the years. The darker areas seen in the same map in the middle of the study area will ripen later and should be collected later in season. With this information, instead of harvesting all orchards together, we may harvest first the ones are not in risk to lose quality or ripen faster due to temperature or other factor (Antunes and Sfakiotakis, 2000).

Principle component analysis showed which of the soil parameters were the most important, for kiwifruit quality and production factor. Strong correlations was found between yield and quality $\left(\mathrm{r}^{2}=0.72\right)$, firmness and ${ }^{\circ}$ Brix maps $\left(\mathrm{r}^{2}=0.88\right)$. The maps derived from kriging for the above parameters were strongly correlated and all other show weak correlation of less than $r^{2}=0.47$.

\section{CONCLUSION}

The use of GIS and geostatistics provides a tool for sustainable production. The availability of software capable of producing attractive maps provides an opportunity to visually communicate production and fruit quality situations to a variety of audiences. It 
will aid practitioners in the design of sustainable management in Integrated Production Programs, particularly on a regional scale. It will provide a way of analyzing and communicating results of regional programs on a continuing basis. The association of environmental factors, landscape features, and cropping patterns with the fruit quality or other production factors can be easily communicated to key managers and decision makers.

A critical assessment of the technology can be summarized in: a) the disadvantage of the cost associated with the time needed to learn the software and to acquire the data; b) the theoretical limitations of geostatistics, because the geostatistical model in which spatial analyses lead to surface maps does not always apply; c) the luck of large farms, young farmers, and well-funded extension programs to apply those tools.

\section{Literature Cited}

Antunes, M.D.C. and Sfakiotakis, E.M. 2000. Effect of high temperature stress on ethylene biosynthesis, respiration and ripening of 'Hayward' kiwifruit. Postharvest Biology and Technology 20:251-259.

Basso, B., Ritchie, J.T., Pierce, F.J., Braga, R.P. and Jones, J.W. 2001. Spatial validation of crop models for precision agriculture. Agricultural Systems 68:97-112.

Bresler, E. 1989. Estimation of statistical moments of spatial field averages for soil properties and crop yields. Soil Science Society of America Journal 53:1643-1645.

Diodato, N. and Ceccarelli, M. 2005. Geographical information systems and geostatistics for modelling radioactively contaminated land areas. Natural Hazards 35:229-242.

Horney, R.D., Taylor, B., Munk, D.S., Roberts, B.A., Lesch, S.M. and Plant, R.E. 2005. Development of practical site specific management methods for reclaiming saltaffected soil. Computers and Electronics in Agriculture 46:379-397.

Kaffka, S.R., Lesch, S.M., Bali, K.M. and Corwin, D.L. 2005. Site-specific management in salt-affected sugar beet fields using electromagnetic induction. Computers and Electronics in Agriculture 46:329-350.

Norton, M.V. 1994. Site Selection and Vineyard development. Kiwifruit Growing and Handling. University of California, Division of Agriculture and Natural Resources. Publication 3344:18.

Panagopoulos, T., Jesus, J., Antunes, M.D.C. and Beltrão, J. 2006. Analysis of spatial interpolation for optimizing management of a salinized field cultivated with lettuce. European Journal of Agronomy 24:1-10.

Panagopoulos, T., Rodrigues, S., Neves, N., Cruz, S. and Antunes, D. 2007. Decision support tools for optimising kiwifruit production and quality. Acta Hort. 753(1):407413.

Yalouris, K.P., Kollias, V., Lorentzos, N.A., Kalivas, D. and Sideridis, A.B. 1997. An integrated expert geographical information system for soil suitability and soil evaluation. Journal of Geographic Information Decision Analysis 1:90-100. 


\section{Figures}
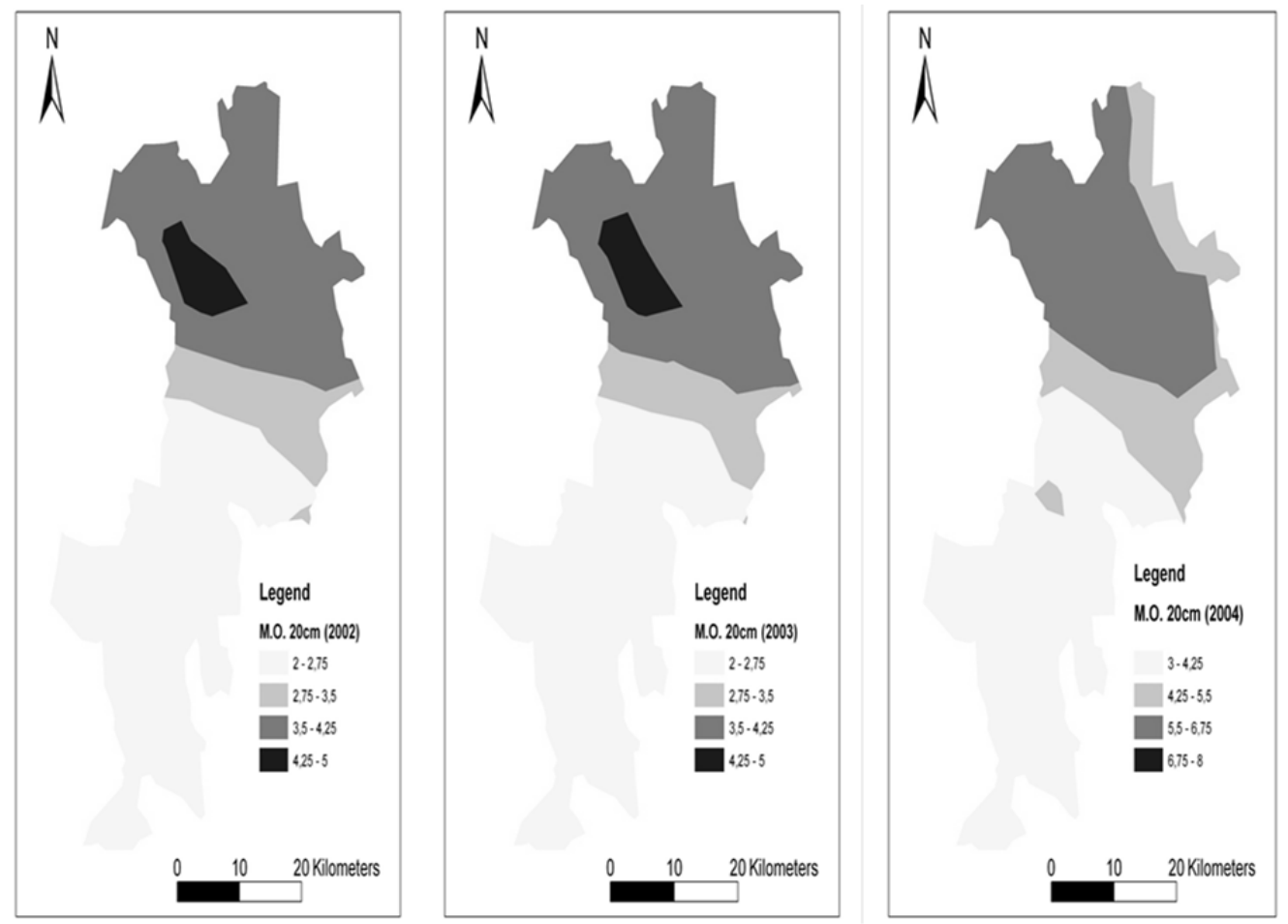

Fig. 1. Spatial distribution and time evolution of soil organic matter from 2002 to 2004.
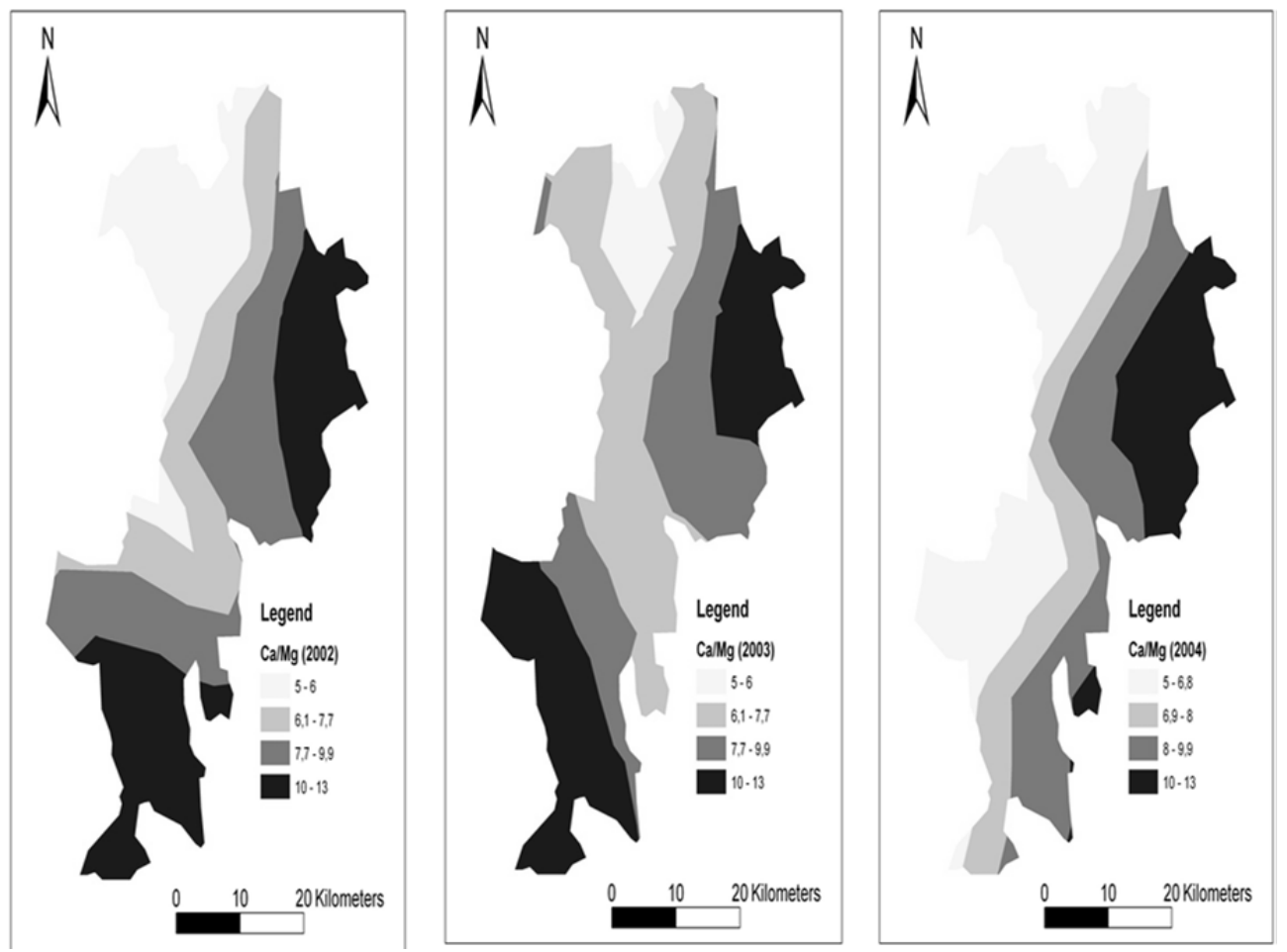

Fig. 2. Spatial distribution and time evolution of the $\mathrm{Ca} / \mathrm{Mg}$ from 2002 to 2004 . 

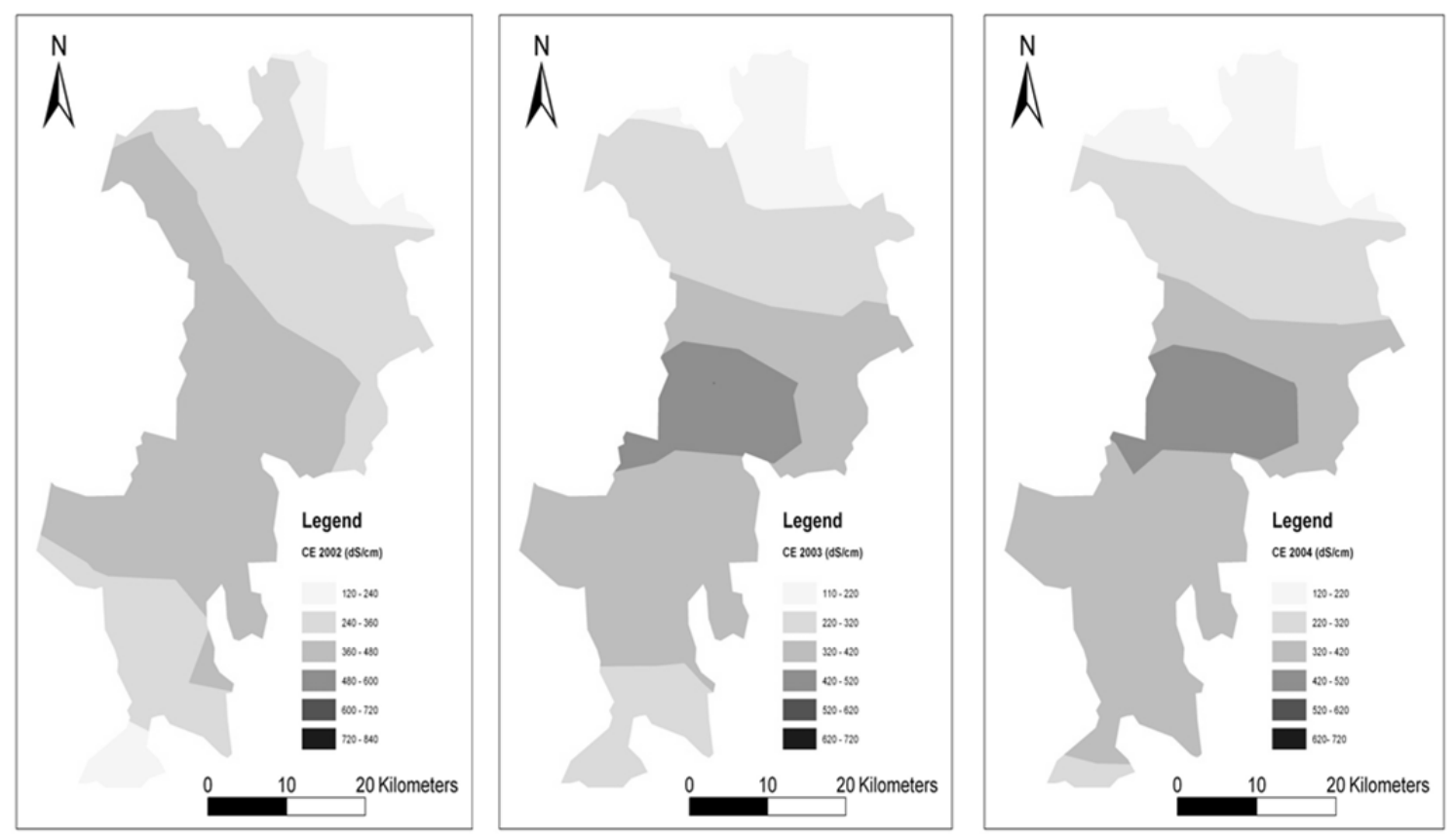

Fig. 3. Spatial distribution and time evolution of the electric conductivity from 2002 to 2004.
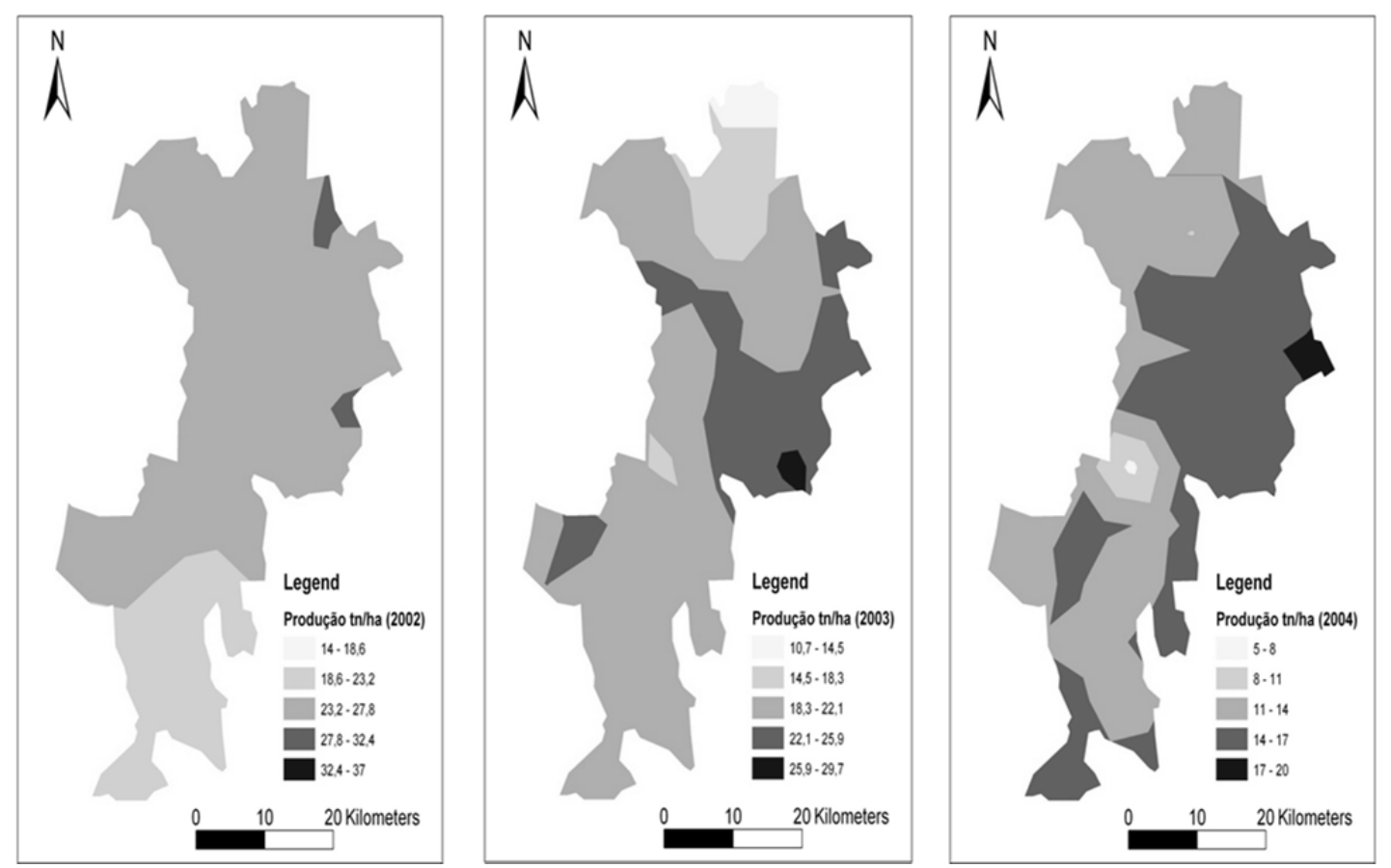

Fig. 4. Spatial distribution and time evolution of the kiwifruit commercial size from 2002 to 2004. 

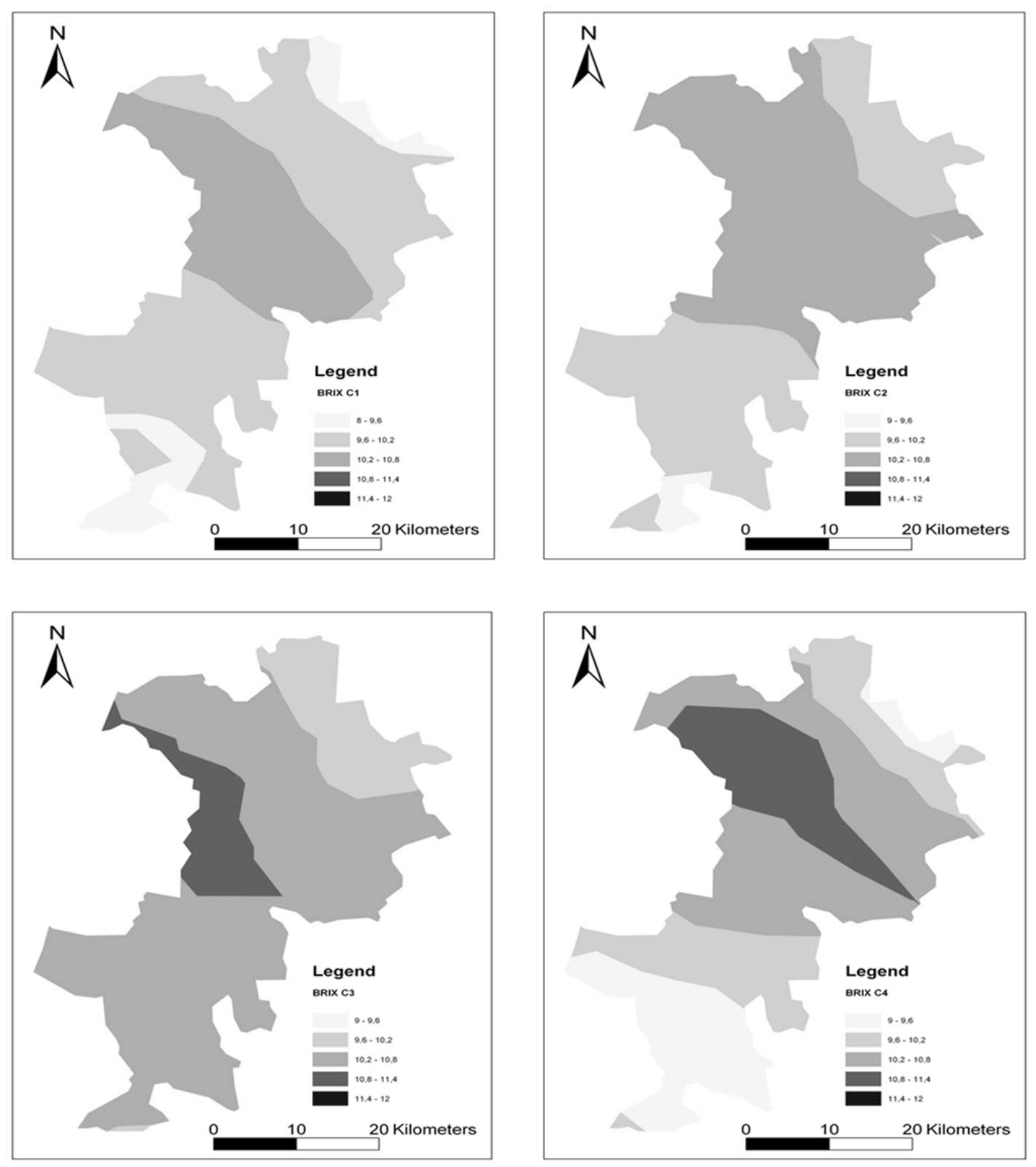

Fig. 5. Spatial distribution of the kiwifruit ${ }^{\circ}$ Brix for four calibers $(\mathrm{C} 1-\mathrm{C} 4)$ at 2004. 